\title{
KONVERSI DATA MATRIKS MODEL CUACA KE CITRA DIGITAL UNTUK PENGIRIMAN MELALUI MEDIA ONLINE
}

\author{
Candra Nur Ihsan \\ Pusat Sains dan Teknologi Atmosfer \\ Lembaga Penerbangan dan Antariksa Nasional \\ Jl. Dr. Djunjunan No. 133 Bandung 40173 \\ candra.nurihsan9@gmail.com
}

\begin{abstract}
Abstrak
Kendala untuk melakukan akses terhadap data cuaca yang berbentuk spasial yang terkompresi dalam format netCDF ada pada ukuran data yang besar untuk ditransimisikan ke pengguna via media online serta format atau kompresi data yang tidak dimengerti oleh aplikasi penjelajah web secara umum. Kendala diatasi dengan melakukan konversi data matriks model cuaca ke citra digital dalam format PNG untuk mendapatkan ukuran yang lebih kecil dan kompresi yang dimengerti penjelajah web. Pengujian hasil plot dari data konversi menunjukan bahwa terdapat kesamaan yang baik (nyaris sempurna) antara plot data matriks cuaca dengan plot yang berasal dari data PNG.
\end{abstract}

Kata kunci:

Konversi, Data Matriks Cuaca, Citra Digital, netCDF, online

\begin{abstract}
Constraints for accessing spatial weather data in the netCDF format lies on the size of the data that have to be transmitted to user via internet and the file format that unknown to most web browsers. This constraint is overcome by converting the weather data to digital imagery in PNG format to obtain smaller size and compression or format that most web browsers understand. Plotting test from weather data and PNG image showing very good similarity.
\end{abstract}

Keywords:

conversion, weather data matriks, digital imagery, netCDF, online.

\section{Pendahuluan}

Pertumbuhan penggunaan internet di Indonesia terus meningkat. Ini terlihat dari statistik pengguna internet di Indonesia. Pada tahun 2013 pengguna internet meningkat dari 12.525.999 jiwa (KOMINFO, 2013) menjadi 132.711 .511 pada tahun 2016 (KOMINFO, 2016) atau lebih dari sepuluh kali lipat. Data tersebut menunjukan bahwa media online menjadi salah satu media yang baik digunakan untuk penyebaran informasi termasuk salah satunya adalah data cuaca.

Untuk menyebarkan informasi melalui media online ada beberapa hal yang harus diatasi. Salah satu kendala yang harus diperhatikan adalah besaran data dari server ke pengguna, karena terkait dengan kecepatan maupun kuota data yang dimiliki pengguna. Namun data cuaca yang dimiliki LAPAN banyak yang berukuran sangat besar terutama yang bersifat spasial dan kombinasi spasial-temporal. Data ini berbentuk kumpulan matriks data, seperti data prediksi cuaca seluruh Indonesia dengan resolusi spasial $5 \mathrm{KM}$ dan resolusi temporal 1 jam dari jam saat memulai prediksi hingga 24 jam kedepan untuk beberapa level ketinggian. Data ini berukuruan rata rata 20 Gigabyte. Bahkan untuk data yang sudah di subset (diambil hanya parameter tertentu) sesuai kebutuhan aplikasi yang akan dibangun LAPAN data masih berukuran rata rata 1,4 Gigabyte. Ini sebuah ukuran yang luar biasa jika ingin diakses secara online melalui internet. Data cuaca ini terkompresi dengan format netCDF.

Pada penelitian ini dilakukan pengembangan metode konversi data cuaca ke dalam citra digital. Tujuan penelitian ini ingin mengetahui sejauh mana kemungkinan memecah dan mengompres data cuaca menjadi citra digital sehingga dapat mengurangi ukuran data yang harus dikirim dari server ke pengguna. Percobaan ini akan mencoba membandingkan teknik yang umum digunakan, yaitu 
konversi data matriks menjadi text dalam bentuk JSON kemudian membandingkan plot data dari hasil konversi ke citra digital dengan plot data yang belum di konversi.

\section{KAJIAN LITERATUR}

Media online sendiri adalah sebutan umum untuk bentuk media yang berbasis telekomunikasi dan multimedia (komputer dan internet). Di dalamnya terdapat portal, website (situs web), radio-online, TVonline, pers online, mail-online, dll, dengan karakteristik masing-masing (Kurniawan, 2005).

NetCDF is a set of software libraries and selfdescribing, machine-independent data formats that support the creation, access, and sharing of arrayoriented scientific data (Russ, 2016).

Citra adalah suatu representasi (gambaran), kemiripan, atau imitasi dari suatu objek. Citra sebagai keluaran suatu sistem perekaman data bersifat optik berupa foto, bersifat analog berupa sinyal-sinyal vidio seperti gambar pada monitor televisi, atau bersifat digital yang dapat langsung disimpan pada suatu media penyimpanan (Sutoyo, 2009). Citra digital sendiri adalah citra yang dapat diolah oleh komputer.

\section{Analisis dan Perancangan}

\section{III.1 Analisis Data Matriks Model Cuaca}

Data matriks model cuaca yang terkompresi dalam netCDF secara umum memilki struktur folder berjenjang (gambar 1). Setiap kelompok data memiliki turunan turunan waktu dan atau elevasi hingga turunan paling akhir adalah data spasial itu sendiri sehingga data membentuk matriks multi dimensi

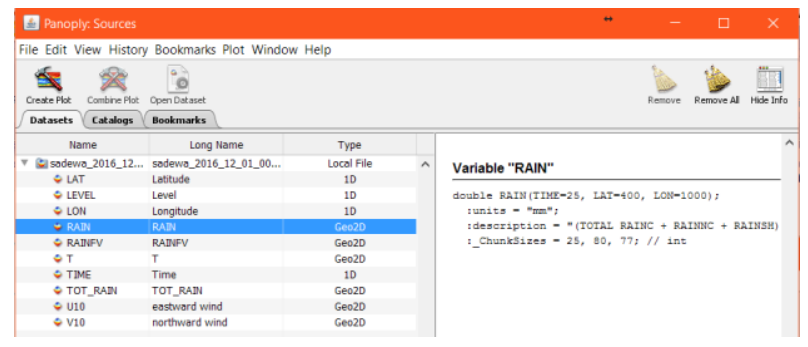

Gambar 1. Struktur Model Data Cuaca

Contoh model cuaca pada gambar 1 menunjukan bahwa model cuaca memiliki variabel seperti LAT, LEVEL, LON, RAIN, RAINFV, T, TIME, TOT_RAIN, U10 dan V10. Dapat dilihat variabel RAIN memiliki bentuk matriks 3 dimensi yaitu time $\mathrm{x}$ lat $\mathrm{x}$ lon $(25 \times 400 \times 1000)$. Dimensi ini menunjukan variable rain memiliki dimensi waktu (time) sebanyak 25 jam, lintang (lat) sebanyak 400 titik dan bujur (lon) sebanyak 1000 titik. Titik lintang dan bujur ini memiliki batasan mulai dari 10 lintang utara dan 95 bujur timur hingga -10 lintang selatan dan 145 bujur timur atau setiap titik mewakili daerah sebesar 0,05 derajat.

Matriks cuaca yang akan dikonversi memiliki bentuk matriks 2 dimensi yaitu sumbu $\mathrm{x}$ dan y atau biasanya di cantumkan sebagai lintang dan bujur. Dari contoh pada gambar 1 dapat dilihat bahwa data cuaca spasial milik LAPAN berukuran 400 x 1000 (2 dimensi terkahir dari variabel RAIN).

\section{III.2 Penentuan Jenis Kompresi Citra Digital}

Secara umum JPG/JPEG, PNG, dan GIF adalah beberapa format citra digital yang biasa digunakan pada media online. Dari beberapa format tersebut PNG dipilih karena PNG memang dirancang untuk bekerja dengan baik pada aplikasi online, sehingga bisa ditampilkan dengan opsi tampilan progresif. PNG juga memiliki pengecekan integritas file dan beberapa kesalahan umum saat transmisi. PNG juga bisa menyimpan data gamma dan kromatisitas untuk pencocokan warna yang lebih baik pada berbagai platform (Duce, 2013)

PNG atau Portable Network Graphics juga memiliki keunggulan kanal alpha yang berguna untuk penyaringan data matriks cuaca. Contohnya setiap data yang bernilai NaN (Not a Number) atau data data yang ada diluar batas pengamatan bisa dihilangkan dengan memberikan nilai 0 pada kanal alpha ini.

PNG memiliki 3 kanal warna yaitu red, green dan blue serta satu kanal transparansi atau kanal aplha. PNG memiliki panjang bit total sebanyak 32 bit dimana setiap kanal memiliki panjang 8 bit atau range nilai dari 0 hingga 255. Kanal kanal ini bisa diilustrasikan sebagai susunan bertumpuk seperti matriks 3 dimensi seperti terlihat pada gambar 2

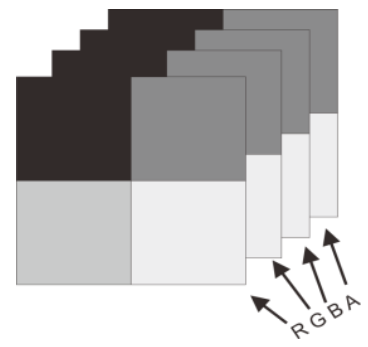

Gambar 2. Ilustrasi PNG 2x2 pixel 


\section{III.3 Perancangan Algoritma Konversi}

Secara umum algoritma konversi ini akan menempatkan setiap titik koordinat matriks cuaca ke dalam kanal dan pixel yang bersesuaian pada citra digital.

Setiap citra digital akan diisi satu data, sehingga dalam satu citra digital hanya akan ada satu jenis variabel data matriks cuaca.

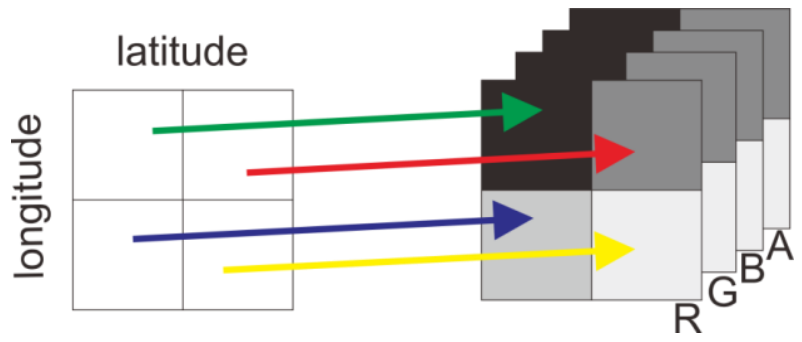

Gambar 3 Penempatan data matriks model cuaca ke pixel PNG

Untuk jenis data yang memiliki lebih dari satu buah matriks seperti data angin yang memiliki dua matriks (besaran dan arah) maka masing masing matriks akan menempati kanal yang berbeda. Kanal yang bisa ditempati adalah kanal red, green dan blue sedang kanal alpha digunakan sebagai penanda nilai $\mathrm{NaN}$ atau nilai yang diluar nilai batas data yang ingin diamati. Alpha 0 berarti transparan atau tidak ada data sedang alpha 255 artinya solid atau ada data.

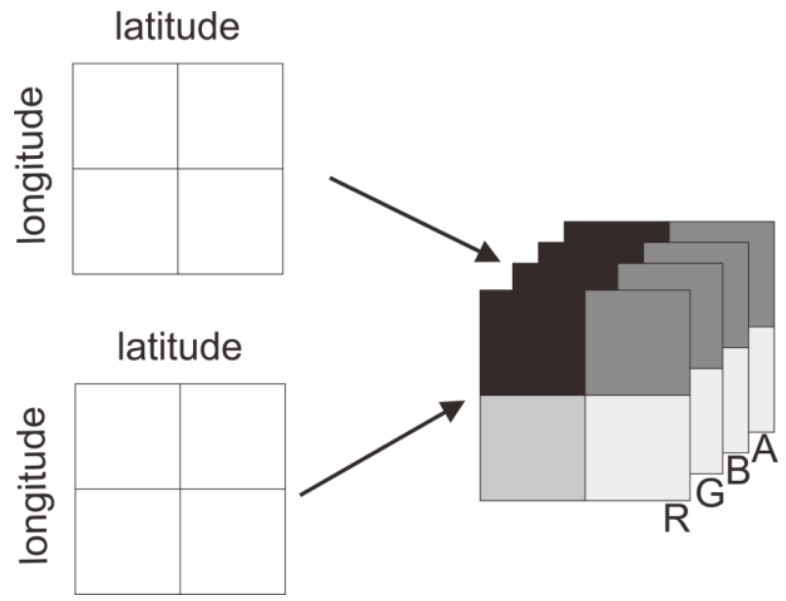

Gambar 4. Penempatan data matriks model cuaca ke pixel PNG untuk data model cuaca yang memiliki lebih dari satu matriks

Nilai yang disimpan dalam citra digital adalah hasil skala linear dari nilai yang terdapat pada matriks cuaca. Nilai ini di konversi ke satu kanal citra PNG yang berkisar dari 0 hingga 255. Skala linear dilakukan dengan menggunakan rumus sebagai berikut:

$v=\left(\frac{\left(x-R_{1 \min }\right)}{\left(R_{1 \max }-R_{1 \min }\right)}\right) \times\left(R_{2 \max }-R_{2 \min }\right)+R_{2 \min }$

$\begin{array}{lll}\text { Dimana } & & \\ \mathrm{V} & = & \text { hasil skala } \\ \mathrm{X} & = & \text { nilai asal } \\ \mathrm{R} \_1 & = & \text { range asal } \\ \mathrm{R} \_2 & = & \text { range skala }\end{array}$

Konversi ini akan mengurangi jumlah bit yang digunakan untuk menyimpan nilai setiap titik pada matriks menjadi hanya 8 bit atau kurang. Dengan cara ini akan dapat mengurangi secara signifikan ukuran file cuaca yang dikirim dibandingkan dengan file berbentuk teks JSON yang menggunakan 8 bit atau kurang untuk karakter dalam satu nilai.

Hal penting sebelum melakukan konversi adalah menyamakan arah incremental data dengan arah incremental media proyeksi. Contohnya menyamakan arah incremental data dengan arah proyeksi bumi mercator agar data yang di kompresi tidak salah atau terbalik.

Pada data matriks model cuaca titik rendah ada di kiri atas dan bertambah ke kanan dan ke bawah sedang pada proyeksi mercator titik rendah ada di kiri bawah dan bertambah ke atas dan ke kanan. Oleh Karena itu data matriks cuaca harus disesuaikan dengan media proyeksi seperti terlihat pada gambar 5.
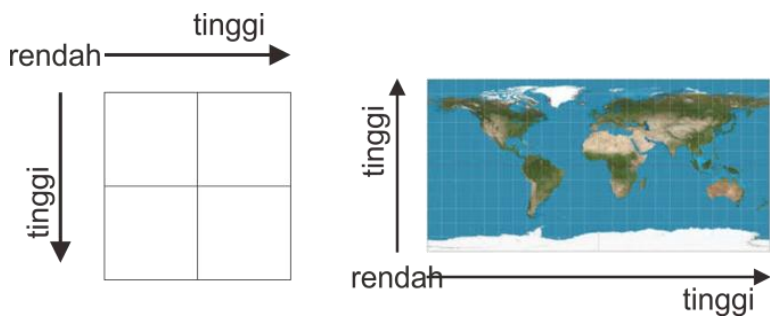

Gambar 5. Arah incremental data setelah disamakan

Untuk proses ploting dari data yang telah dikonversi diperlukan beberapa informasi yang dibawa dari data matriks model cuaca ke konversi citra digital.

1 Informasi tersebut diantaranya adalah: Batasan latitude dan longitude (bounding box).

2 Batasan nilai maximum dan minimum. 
3 Informasi mengenai data (nama, jenis, satuan)

4 Informasi lain yang dianggap perlu untuk proses ploting.

Semua karakter dari informasi yang ditambahkan akan dikonversi menjadi nilai ascii. Karakter karakter informasi akan menempati kanal red, green dan blue secara berurut jika ketiga kanal sudah terisi maka bergeser ke pixel berikutnya hingga semua karakter yang terdapat di informasi tambahan terkonversi menjadi ascii hasil konversi karakter karakter ini akan terlihat seperti gambar 6, hasil konversi ini akan ditambahkan ke citra digital sebagai referensi saat ploting pada media proyeksi.

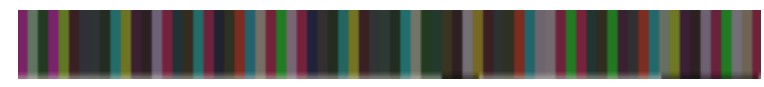

Gambar 6. Hasil konversi karakter karakter dari informasi tambahan

Berdasarkan analisis data matriks cuaca, analisis citra digital PNG, serta perancangan algoritma, maka dibuat sebuah algoritma yang dapat digambarkan seperti yang terlihat pada gambar 7:

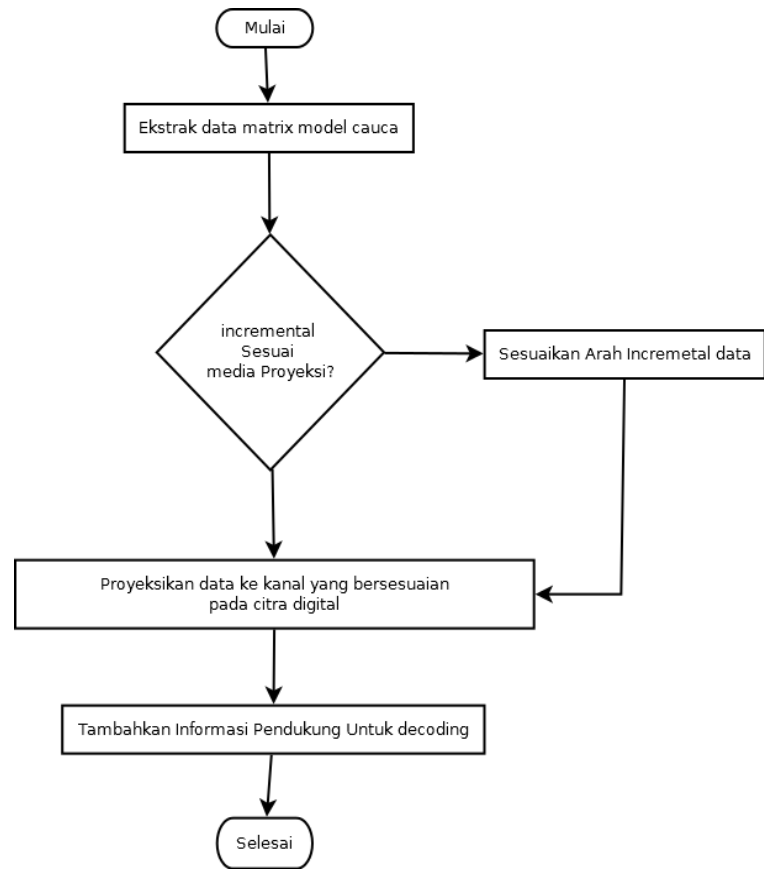

Gambar 7. Algoritma konversi

\section{III.4 Implementasi dan pengujian}

Implementasi algoritma konversi dilakukan di pemrograman python dengan library utama seperti netCDF,PIL, dan Numpy.

Untuk menjawab permasalahan yang diungkapkan di pendahuluan maka metode akan diuji dengan:

1. Membandingkan ukuran file data matriks cuaca yang dikonversi ke citra digital dengan data matriks cuaca yang dikonversi menjadi text dalam format JSON.

2. Melakukan plot data matriks cuaca dan plot data hasil konversi matriks cuaca serta membandingkan keduanya. Pembandingan akan diukur dengan metode MSE (mean squared error) dan SSIM (Structural Similarity Measure).

\section{III.5 Pengujian dengan MSE}

MSE digunakan untuk mengukur kesamaan antara dua gambar dan menghasilkan nilai kuantitatif yang menunjukan tingkat error dari dua gambar yang dibandingkan (Wang, 2019).

$M S E=\frac{1}{M \times N} \sum_{i=\mathrm{n}}^{M-1} \sum_{j=0}^{N-1}[I(i, j)-K(i, j)]^{2}$

Dimana

$\mathrm{M}$ dan $\mathrm{N}$ adalah ukuran panjang dan lebar citra $\mathrm{I}(\mathrm{i}, \mathrm{j})=$ citra di titik $\mathrm{i}, \mathrm{j}$ hasil plot matriks model cuaca $K(i, j)=$ citra di titik $\mathrm{i}, \mathrm{j}$ hasil plot dari citra hasil konversi

\section{III.6 Pengujian dengan SSIM}

SSIM mengukur kemiripan citra berdasarkan struktur yang dimiliki oleh kedua citra digital yang dibandingkan (Wang, 2004).

$\operatorname{SSIM}(x, y)=\frac{\left(2 \mu_{x} \mu_{y}+c_{1}\right)\left(2 \sigma_{x y}+c_{2}\right)}{\left(\mu_{x}^{2}+\mu_{y}^{2}+c_{1}\right)\left(\sigma_{x}^{2}+\sigma_{y}^{2}+c_{2}\right)}$

Dimana

$\begin{array}{ll}x, y & =\text { Dimensi citra } \\ \mu_{x} & =\text { Rata rata } \mathrm{x} \\ \mu_{y} & =\text { Rata rata } \mathrm{y} \\ \sigma_{x}^{2} & =\text { Varian } \mathrm{x}\end{array}$
Candra Nur Ihsan

Jurnal Ilmiah Teknologi Informasi Terapan

Volume IV, No 3, 15 Agustus 2018 
$\sigma_{y}^{2}=$ Varian $\mathrm{y}$

$\sigma_{x y}=$ Kovarian $\mathrm{x}$ dan $\mathrm{y}$

$c_{1}, c_{2}=$ variabel penyetabil penyebut

\section{III.7 Hasil Dan Pembahasan}

Implementasi algoritma di ujicobakan pada data cuaca model WRF milik LAPAN periode desember 2016.

A. Pembadingan JSON dan PNG

Perbandingan hasil konversi citra digital dan JSON menunjukan bahwa citra digital PNG memiliki ukuran jauh lebih kecil.

Tabel 1. Perbandingan Ukuran File Hasil Konversi Ke Citra Digital Dan Ke Text Dengan Format JSON

\begin{tabular}{|l|l|l|}
\hline & JSON & PNG \\
\hline Rata Rata & $2.03 \mathrm{Mb}$ & $0.05 \mathrm{Mb}$ \\
\hline Maximum & $2.07 \mathrm{Mb}$ & $0.13 \mathrm{Mb}$ \\
\hline Minimum & $2 \mathrm{Mb}$ & $0.01 \mathrm{Mb}$ \\
\hline
\end{tabular}

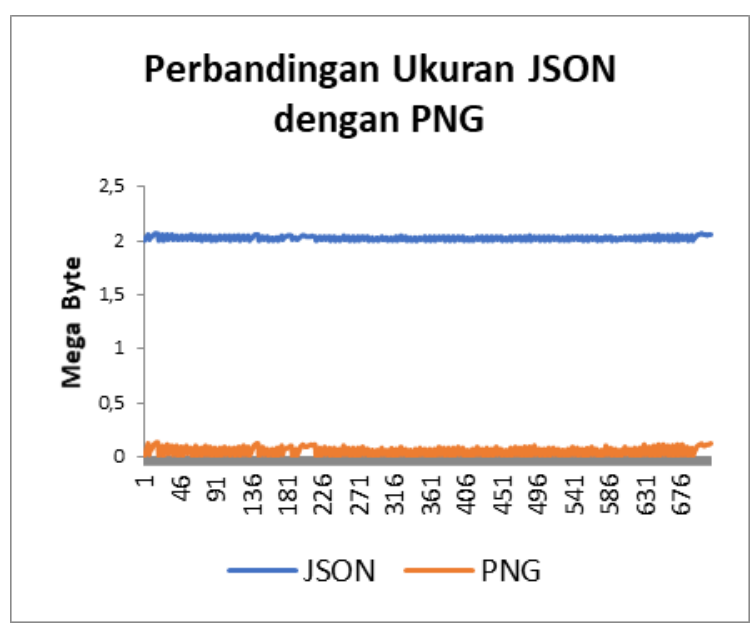

Gambar 8. Perbandinga ukuran file PNG dan hasil konversi ke text dengan format JSON

Dari tabel 1 terlihat jika rata rata selisih ukuran file PNG dengan JSON adalah sebesar $1,98 \mathrm{Mb}$ atau hanya menggunakan bandwidth skitar 2,5\% jika dibandingkan dengan data JSON.
B. Perbandingan Visual

Dari gambar 9, gambar 10 dan gambar 11 terlihat kesamaan hasil plot dengan menggunakan data matriks cuaca dengan hasil plot menggunakan data PNG.
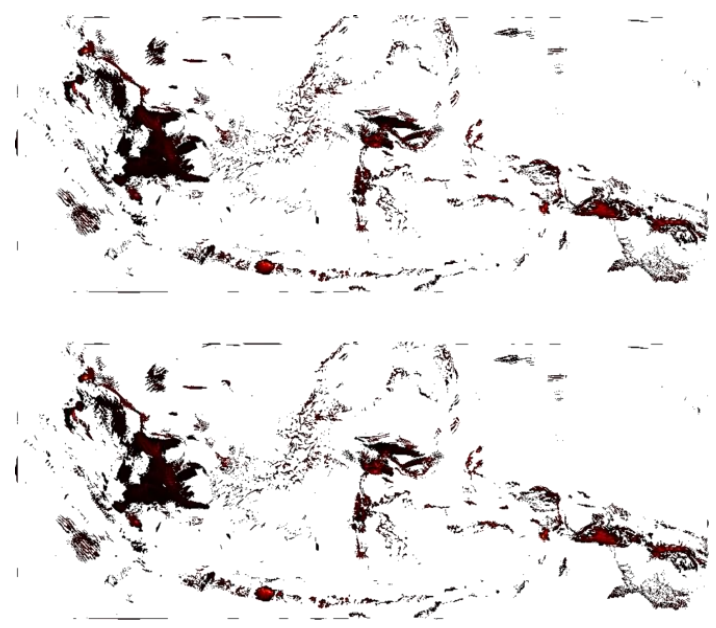

Gambar 9. Atas plot data matriks cuaca, bawah plot data PNG
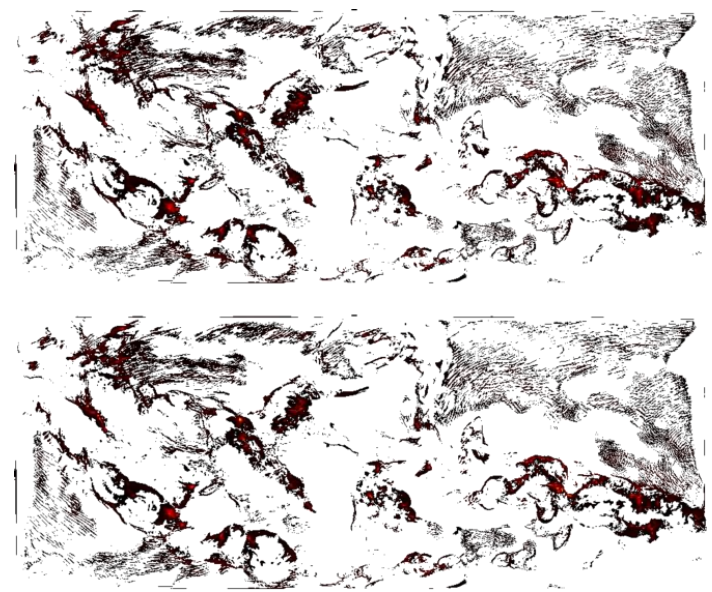

Gambar 10. Atas plot data matriks cuaca, bawah plot data PNG
Candra Nur Ihsan

Jurnal Ilmiah Teknologi Informasi Terapan

Volume IV, No 3, 15 Agustus 2018 


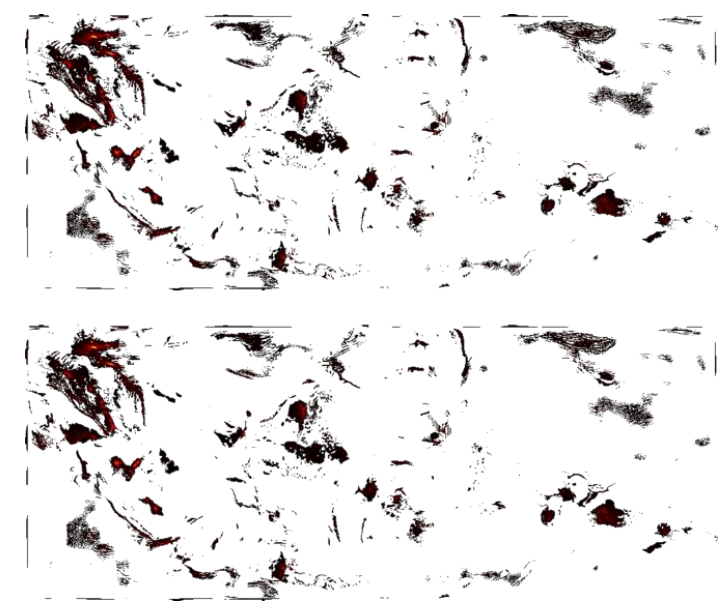

Gambar 11. Atas plot data matriks cuaca, bawah plot data PNG

Komparasi citra diatas merupakan penilaian subjektif maka kebenarnya bersifat subjektif pula. Untuk itu perlu adanya alat ukur kuantitatif yang bisa digunakan untuk mengukur kesamaan kedua plot tersebut. Alat ukur ini diantaranya adalah MSE dan SSIM.

\section{Komparasi dengan MSE}

—Berikut hasil perbandingan MSE pada citra plot yang berasal dari matriks model cuaca dan yang berasal dari eitra hasil konversiPNG.

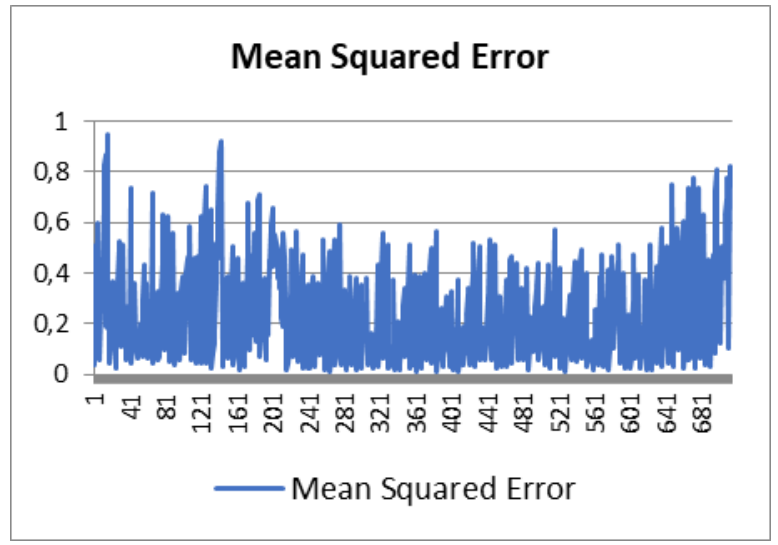

Gambar 12. Perbandingan dengan MSE
Tabel 2. Resume Perbandingan Dengan MSE

\begin{tabular}{|c|c|}
\hline & \multicolumn{2}{|c|}{ Nilai } \\
\hline Rata Rata & 0.246 \\
\hline Maximum & 0.951 \\
\hline Minimum & 0.01 \\
\hline
\end{tabular}

Semakin dekat dengan 0 nilai MSE semakin baik dimana 0 adalah sempurna atau tanpa ada perbedaan, sedang semakin lebih besar dari 1 maka semakin besar ketidak samaanya. Dilihat dari pola perhitungan MSE pada gambar 11 dan resume perbandingan pada tabel 2 dapat disimpulkan bahwa nilai rata rata kemiripan adalah 0,246 dengan nilai maximum yang masih kurang dari 1 yang berarti sangat baik.

D. Komparasi dengan SSIM

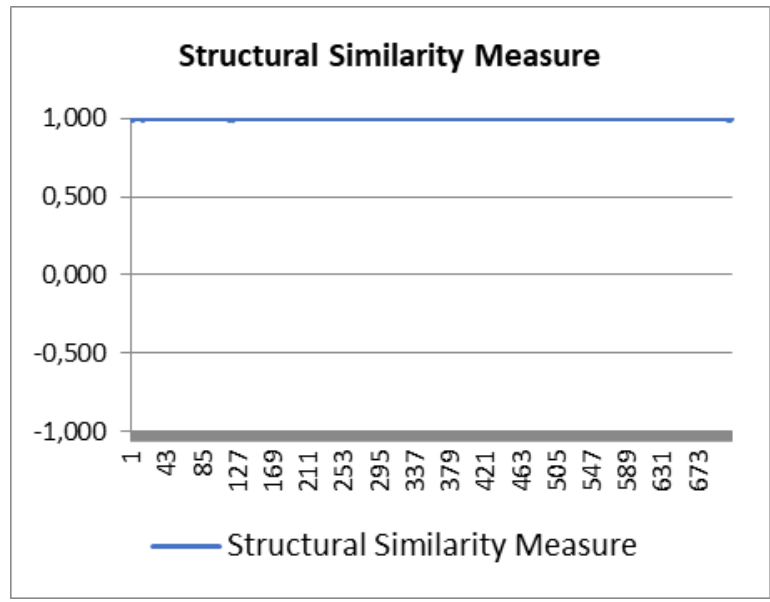

Gambar 13. Perbandingan Dengan SSIM

Tabel 3. Resume Perbandingan dengan SSIM

\begin{tabular}{|l|l|}
\hline & Nilai \\
\hline Rata Rata & 0.997 \\
\hline Maximum & 1.000 \\
\hline Minimum & 0.986 \\
\hline
\end{tabular}

Nilai SSIM berkisar antara -1 hingga 1 dimana 1 menggambarkan nilai kemiripan yang sempurna. Berdasarkan hasil dari gambar 12 dapat dilihat bahwa nilai perbandingan dari data yang diamati hampir
Candra Nur Ihsan

Jurnal Ilmiah Teknologi Informasi Terapan

Volume IV, No 3, 15 Agustus 2018 
mendekati 1 dengan maksimum ada di 1 yang artinya sempurna serta 0.986 sebagai nilai minimum yang juga sangat dekat dengan 1 .

\section{KESIMPULAN DAN SARAN}

Dari hasil pengujian menunjukan bahwa citra PNG hasil konversi jauh lebih efisien di banding metode pengirman data dengan matriks text.

Perbandingan plot nilai asli data dengan nilai dari hasil konversi citra digital menunjukan bahwa citra digital memiliki kesamaan yang nyaris sempurna.

Nilai konversi citra digital bisa digunakan untuk keperluan visualisasi terutama oleh aplikasi aplikasi berbasis online juga bisa dikembangkan untuk menggunakan bit bit yang belu digunakan pada penelitian ini.

\section{REFERENSI}

KOMINFO. (2013). Data \& Statistik KOMINFO. Retrieved June 1, 2017, from http://statistik.kominfo.go.id/site/data?idtree $=42$ $4 \&$ iddoc $=1186 \&$ data-data_page $=15$

KOMINFO. (2016). Data \& Statistik KOMINFO. Retrieved June 1, 2017, from https://statistik.kominfo.go.id/site/data?idtree $=4$ $24 \&$ iddoc $=1516 \&$ data-data_page $=2$

Kurniawan, A. (2005). Transformasi Pelayan Publik. Pembaruan:Yogyakarta.

Rew, R., Davis, G., Emmerson, S., Davies, H., Hartnett, E., Heimbigner, D., \& Fisher, W. (2016). NetCDF: Introduction and Overview. Retrieved July 27, 2017, from http://www.unidata.ucar.edu/software/netcdf/do cs/index.html

Sutoyo, T., Mulyanto, E., Suhartono, V., Nurhayati, O. D., \& Wijanarto, M. (2009). Teori Pengolahan Citra Digital. Andi Yogyakarta.

Duce, D. (2003). Portable Network Graphics (PNG) Specification (Second Edition). w3c. Retrieved from http://www.w3.org/TR/2003/REC-PNG20031110/

Wang, Z., \& Bovik, A. C. (2009). Mean Squared Error: Love It or Leave It? IEEE Signal Processing Magazine, 26(January), 98-117. Retrieved from http://ieeexplore.ieee.org/lpdocs/epic03/wrapper .htm?arnumber $=4775883$
Wang, Z., Bovik, A. C., Sheikh, H. R., \& Simoncelli, E. P. (2004). Image quality assessment: From error visibility to structural similarity. IEEE Transactions on Image Processing, 13(4), 600612.

\section{Candra Nur Ihsan}

Jurnal Ilmiah Teknologi Informasi Terapan

Volume IV, No 3, 15 Agustus 2018 